OPEN ACCESS

Check for updates

For numbered affiliations see end of the article.

Correspondence to: Y Tsugawa ytsugawa@mednet.ucla.edu (or @ytsugawa1 on Twitter: ORCID 0000-0002-1937-4833)

Additional material is published online only. To view please visit the journal online.

Cite this as: $B M J$ 2020;371:m4381 http://dx.doi.org/10.1136/bmj.m4381

Accepted: 12 November 2020

\title{
Patient mortality after surgery on the surgeon's birthday: observational study
}

\author{
Hirotaka Kato, ${ }^{1,2}$ Anupam B Jena, 3,4,5,6 Yusuke Tsugawa ${ }^{1,7}$
}

\begin{abstract}
OBJECTIVE

To determine whether patient mortality after surgery differs between surgeries performed on surgeons' birthdays compared with other days of the year.
\end{abstract}

DESIGN

Retrospective observational study.

SETTING

US acute care and critical access hospitals.

\section{PARTICIPANTS}

$100 \%$ fee-for-service Medicare beneficiaries aged 65 to 99 years who underwent one of 17 common emergency surgical procedures in 2011-14.

\section{MAIN OUTCOME MEASURES}

Patient postoperative 30 day mortality, defined as death within 30 days after surgery, with adjustment for patient characteristics and surgeon fixed effects. RESULTS

980876 procedures performed by 47489 surgeons were analyzed. $2064(0.2 \%)$ of the procedures were performed on surgeons' birthdays. Patient characteristics, including severity of illness, were similar between patients who underwent surgery on a surgeon's birthday and those who underwent surgery on other days. The overall unadjusted 30 day mortality on the operating surgeon's birthday was $7.0 \%(145 / 2064)$ and that on other days was $5.6 \%$ (54824/978 812). After adjusting for patient characteristics and surgeon fixed effects (effectively comparing outcomes of patients treated by the same surgeon on different days), patients who underwent surgery on a surgeon's birthday exhibited higher mortality compared with patients who underwent surgery on other days (adjusted mortality rate, $6.9 \%$ $v 5.6 \%$; adjusted difference $1.3 \%, 95 \%$ confidence

\section{WHAT IS ALREADY KNOWN ON THIS TOPIC}

Distractions due to clinical or personal events in the operating room are common Although laboratory experiments have shown that distractions can have a detrimental effect on surgeons' performance, empirical evidence using real world data is limited about how distractions in surgery affect patient outcomes Operations performed on surgeons' birthdays might provide a unique opportunity to assess the relationship between personal distractions and patient outcomes, but the association between surgeon's birthday and patient mortality has not been investigated

\section{WHAT THIS STUDY ADDS}

Patients who underwent common emergency surgical procedures on the operating surgeon's birthday showed higher 30 day mortality compared with patients who underwent surgery on other days of the year

These findings suggest that a surgeon's performance might be affected by potentially distracting life events that are not directly related to work

interval $0.1 \%$ to $2.5 \% ; \mathrm{P}=0.03)$. Event study analysis of patient mortality by day of surgery relative to a surgeon's birthday found similar results.

\section{CONCLUSIONS}

Among Medicare beneficiaries who underwent common emergency surgeries, those who received surgery on the surgeon's birthday experienced higher mortality compared with patients who underwent surgery on other days. These findings suggest that surgeons might be distracted by life events that are not directly related to work.

\section{Introduction}

Surgery plays a fundamental role in healthcare, with an estimated $11-30 \%$ of the global burden of diseases requiring surgical care, anesthesia, or both. ${ }^{1-3}$ The quality of surgical care is not always optimal; however, $5-10 \%$ of patients who undergo inpatient surgery die after the procedure, ${ }^{4-9}$ and $20-30 \%$ of patients experience complications. $.^{4-8} 10-15$ Of those complications, 40-60\% are considered avoidable, ${ }^{101617}$ and $20-40 \%$ of deaths after surgical procedures are estimated to be preventable. ${ }^{10}$

Although many system level and physician level factors influence surgical outcomes, ${ }^{18-20}$ the role of distractions has received little empirical investigation. Distractions are common in the operating room, including noise (eg, calls from ward, beeper pages), problems with the equipment, and conversations not pertinent to the surgical procedure. ${ }^{21-24} \mathrm{Al}-$ though laboratory experiments have shown that distractions can have a detrimental effect on surgeons' performance, such as time to task completion, surgical errors, and accuracy, ${ }^{25-28}$ empirical evidence using real world data is limited as to how distractions during surgery affect patient outcomes. Outside of healthcare, studies have found that distractions due to extraneous factors, including outdoor temperatures and losses of local sports teams, have a meaningful impact on people's decision making process. ${ }^{29-31}$ However, as surgeon level information on potentially distracting events is difficult to obtain, how distractions caused by extraneous factors affect surgeons' performance and patient outcomes has not been investigated.

Operations performed on birthdays of surgeons might provide a unique opportunity to assess the relationship between personal distractions and patient outcomes, under the hypothesis that surgeons may be more likely to become distracted or feel rushed to finish procedures on their birthdays, and therefore patient outcomes might worsen on those days. To test this hypothesis, we used national data on Medicare beneficiaries aged 65 to 99 years in the US who underwent one of 17 common surgeries between 2011 
and 2014, linked to information on surgeon birthdays, to examine whether patients' postoperative mortality differed for surgeries performed on surgeons' birthdays versus other days of the year.

\section{Methods}

\section{Data sources}

We analyzed $100 \%$ of Medicare fee-for-service beneficiaries aged 65 to 99 treated at acute care and critical access hospitals in 2011-14. To minimize the impact of potential selection bias from surgeons choosing patients based on illness severity, or patients choosing surgeons based on their preference, we focused our analyses on emergency procedures (defined as emergent or urgent admissions or admissions from trauma centers) identified using claim inpatient admission type code. ${ }^{32} 33$ To ensure that procedures were emergencies, we also restricted analysis to surgeries performed within three days of hospital admission. ${ }^{34-36}$ To avoid patients' care preferences (including end-of-life care) affecting postoperative mortality, we excluded patients with cancer and patients discharged to hospice care. We also excluded patients who left hospital against medical advice. To allow for sufficient follow-up after surgery, we excluded from our analyses those patients who underwent procedures in December 2014.

We identified all patients who underwent one of 17 major surgical procedures: four common cardiovascular surgeries examined in previous studies (carotid endarterectomy, heart valve procedures, coronary artery bypass grafting, and abdominal aortic aneurysm repair), ${ }^{18323738}$ and the 13 most common non-cardiovascular surgeries in the Medicare population (hip and femur fracture, colorectal resection, cholecystectomy and common duct procedures, excision of peritoneal adhesions, fracture or dislocation of lower extremity other than hip or femur, lung resection, amputation of lower extremity, nephrectomy, appendectomy, small bowel resection, spinal fusion, gastrectomy, and splenectomy). Supplementary eTable $1 \mathrm{~A}$ provides a list of ICD-9 (international classification of disease, ninth revision) codes.

\section{Surgeon characteristics}

We used the national provider identifier listed in the operating physician field of the inpatient claim to identify the surgeon who performed each procedure, an approach validated in previous studies. ${ }^{18} 353739$ Surgeon characteristics were obtained from the Centers for Medicare \& Medicaid Services' MD-PPAS file, which includes information on the surgeon's birthday, sex, and specialty. About $98 \%$ of our Medicare beneficiary data could be linked to the MD-PPAS file using the national provider identifier. Data on surgeons' birthdays in MD-PPAS file were extracted from the Medicare Provider Enrollment, Chain, and Ownership System, and the proportion of missing data on birthday was $0.01 \%$ in $2017 .{ }^{40}$

\section{Patient outcomes}

The primary outcome was 30 day mortality, defined as death within 30 days after surgery. Information on death dates, including out of hospital deaths, was available in the Medicare Beneficiary Summary Files, where more than $99 \%$ of death dates are verified using death certificates. ${ }^{41}$ We excluded less than $1 \%$ of patients whose death dates were not verified.

\section{Adjustment variables}

Depending on the model, we adjusted for patient characteristics and hospital or surgeon fixed effects. Patient characteristics included the type of procedure (indicator variables for 17 surgical procedures), age (a continuous variable with quadratic and cubic terms, allowing for a non-linear relationship), sex, race and ethnicity (non-Hispanic white, non-Hispanic black, Hispanic, other), indicator variables for 24 comorbidities (Elixhauser comorbidity index), ${ }^{42}$ median household income estimated from residential zip codes (as a continuous variable with quadratic and cubic terms), an indicator for dual Medicaid coverage, and year and day of the week of surgery (to allow for the possibility that patients undergoing weekend surgery might have worse outcomes ${ }^{43}$ ). Hospital fixed effects were indicator variables for each hospital, and surgeon fixed effects were indicator variables for each surgeon. Including hospital or surgeon fixed effects as adjustment variables in regression analysis controlled for both time invariant measured and unmeasured characteristics of hospitals or surgeons, including differences in patient populations, effectively comparing outcomes of patients who were treated at the same hospital or those who were operated on by the same surgeon. ${ }^{4546}$

\section{Statistical analysis}

We examined whether surgeons' birthdays were evenly distributed throughout the year and compared patient characteristics and patients' illness severity on an operating surgeon's birthday and other days, to investigate whether patients' illness severity differed based on the date of surgery. To estimate illness severity for each patient, we regressed 30 day mortality on patients' characteristics using a logistic regression model and estimated the predicted probability of 30 day mortality for each patient. Additionally, we evaluated the number of procedures per surgeon on and around his or her birthday to examine whether surgeons changed their decision to perform surgeries (eg, their operative volume) on their birthdays. Finally, we compared the characteristics of surgeons who performed procedures on their birthdays with those who did not.

Next, we compared the operative mortality of patients who underwent surgery on an operating surgeon's birthday with patients whose operation was performed on other days of the year. We constructed three regression models. Model 1 adjusted for patient characteristics only. Model 2 adjusted for all variables 
in model 1 plus hospital fixed effects, effectively comparing patient outcomes within the same hospital. Model 3 adjusted for all variables in model 1 plus surgeon fixed effects, a within surgeon analysis that compared outcomes for surgeries performed on surgeons' birthdays versus other days on which the same surgeon operated. The analyses adjusting for hospital fixed effects (model 2) compared outcomes of patients treated at the same hospital and therefore relied on variation between surgeons within the same hospital. In contrast, the analyses adjusting for physician fixed effects (model 3) compared outcomes of patients who underwent surgery by the same surgeon, effectively addressing the research question of whether individual surgeons perform differently on their birthday compared with other days of the year. We used multivariable linear probability models (fitting ordinary least squares to binary outcomes) for the main analyses to overcome the issue of complete or quasicomplete separation of logistic regression models, owing to a large number of fixed effects. ${ }^{4748}$ Standard errors were clustered at the surgeon level to account for potential correlation between patient outcomes within the same surgeon. After fitting regression models, we calculated adjusted patient outcomes using the marginal standardization form of predictive margins. ${ }^{49}$

Finally, we conducted an event study analysis to investigate how patient 30 day mortality differed around surgeons' birthdays. We regressed patient 30 day mortality on a set of relative date indicators within two weeks before and after a surgeon's birthday (using other days of the year as the reference category), adjusting for patient characteristics and surgeon fixed effects (model 3). To avoid unstable estimates from relatively small sample sizes for any given day, we grouped every two days into a single category for the event study analysis (we did not group days for all other analyses). We then calculated adjusted 30 day mortality rates for each date within two weeks of the operating surgeon's birthday and compared them with adjusted mortality rates of patients who underwent a procedure on other days of the year.

\section{Secondary analyses}

We conducted a series of secondary analyses.

- To examine whether our findings were sensitive to the selection of follow-up periods for calculating patient mortality, we reanalyzed the data using in-hospital mortality instead of 30 day mortality as an outcome.

- To address the possibility that some surgeons might manipulate the timing of operations (eg, postpone non-urgent surgical procedures) based on their birthday, in our regression analyses, we tested whether findings were affected by additional adjustment for the timing of surgery (date of surgery relative to admission date).

- To test whether our findings were affected by including both hospital and surgeon fixed effects in the same regression models.
- To test the possibility that a small number of outlier surgeons might dominate our findings, we reanalyzed the data after excluding the top $1 \%$ of surgeons with the highest patient mortality.

- We used logistic regression models instead of linear probability models, adjusting for patient characteristics and hospital or surgeon fixed effects.

- To test whether our findings were sensitive to the model specification, we fitted random effects models instead of fixed effects models, adjusting for patient characteristics and hospital or surgeon random effects.

- To address the possibility that some surgeons might choose not to work on their birthdays, we reanalyzed our data restricting to surgeons who performed procedures on their birthdays in our sample (ie, excluding surgeons who performed no surgeries on their birthdays). This problem was also addressed by including surgeon fixed effects in model 3.

- To examine the possibility that other events on surgeons' birthdays, other than the birthday itself, might affect patient mortality, we reanalyzed the data after additionally adjusting for the day of the year of surgery (ie, indicator variables for the calendar date).

- As there might be outlier birthdays on which a larger than expected number of surgeons reported birthdays, we reanalyzed the data after excluding surgeons who were born on these days.

- We conducted a stratified analysis by the individual procedures received by patients, adjusted for patient characteristics and surgeon fixed effects (model 3). To avoid unstable estimates as a result of small sample sizes, we restricted our analyses to procedures for which the number of surgeries was more than 10 on a surgeon's birthday.

- To test whether our findings were explained by random chance, we examined the association between surgeons' half birthdays (calculated by adding 183 days to operating surgeons' birthday) and patient mortality.

- For the same reason, we also conducted a simulation analysis assigning randomly generated "pseudo-birthdays" to surgeons and examined the association between these pseudo-birthdays and 30 day mortality in 1000 estimations, adjusted for patient characteristics and surgeon fixed effects. We then compared the estimated difference in patient mortality between birthday and non-birthday surgeries generated through this simulation with the estimates obtained in our baseline multivariable analysis that included patient characteristics and surgeon fixed effects (model 3).

- We reanalyzed the data using more restrictive definitions of emergency surgeries, defined as 10 procedures with the highest average mortality, or patients with the highest severity of illness (in the top $25 \%$ of predicted 30 day mortality). 
- We examined the association between surgeons' birthdays and patient mortality for elective procedures (defined as surgeries performed during elective admissions), and between surgeons' birthdays and complications for emergency procedures, defined as whether patients experienced at least one complication measure related to surgeons' performance in Agency for Health Research and Quality's Patient Safety Indicators: retained surgical item or unretrieved device fragment count (PSI 05), perioperative hemorrhage or hematoma (PSI 08), and postoperative wound dehiscence (PSI 14). ${ }^{33}$

- To test the hypothesis that surgeons might feel particularly rushed to complete surgeries on birthdays with a high volume of procedures, we calculated the number of total procedures (including both elective and emergency) performed by each surgeon. After adjusting for potential confounders (including hospital or surgeon fixed effects), we then compared postoperative mortality of patients who underwent emergency surgeries among three groups: patients who underwent surgery on the operating surgeon's birthday, when the surgeon was performing a high volume (above mean) of procedures on that day; patients who underwent surgery on the operating surgeon's birthday, when the surgeon was performing a low volume (below mean) of procedures on that day; and patients who underwent surgery on days other than the operating surgeon's birthday.

- We examined whether the association between surgeon's birthday and patient mortality varied according to whether an operation occurred on a special ("milestone") birthday, hypothesizing that these birthdays might lead to greater distraction. We investigated the association between 30 day mortality and surgeon's birthday at milestone ages (ie, 40, 50, and 60 years). Finally, we investigated whether the association between 30 day mortality and operation on a surgeon's birthday varied according to whether the birthday occurred on a Friday versus on a Monday to Thursday, hypothesizing that Friday birthdays might be associated with greater distraction if celebratory activities were more likely to occur.

We used SAS version 9.4 (SAS Institute) for data preparation and Stata version 14 (Stata) for all analyses.

\section{Patient and public involvement}

Although we support the importance of patient and public involvement, this was a secondary data analysis of existing claims data where the records were not available for patients or members of the public for analysis and as such it was not practical to involve them as members of this research study.

\section{Results}

\section{Characteristics of study population}

The study sample included 980876 procedures performed by 47489 surgeons, whose birthdays were evenly distributed throughout the year (supplementary eFigure 1). Among those procedures, 2064 (0.2\%) were performed on surgeons' birthdays. Patients who underwent operations on surgeons' birthdays had similar characteristics, including personal, comorbidities, procedure type, and predicted mortality, to those who underwent operations on other days (table 1 and supplementary eTable 2). For example, the mean predicted mortality rate of patients who underwent surgery on surgeons' birthdays was similar to that of patients who underwent surgery on other days (5.5\% v 5.6\%; $\mathrm{P}=0.35)$. Moreover, no significant difference was observed in the distributions of predicted mortality between patients who underwent surgery on surgeons' birthdays and those who underwent surgery on other days (supplementary eFigure 2). Predicted mortality was also similar for operations performed in the 14 days before or after the surgeons' birthdays (supplementary eFigure 3). The average number of surgical procedures performed by each surgeon was similar between birthdays and other days (supplementary eFigure 4). These findings suggest that surgeons did not selectively choose which patients to operate on on their birthdays on the basis of patient characteristics, including illness severity. Surgeons who worked on their birthday were on average older and more likely to be men (supplementary eTable 3), although these differences did not affect the results of analyses that adjusted for surgeon fixed effects (effectively comparing outcomes of patients treated by the same surgeon).

\section{Mortality rates}

The overall unadjusted 30 day mortality of patients on the surgeon's birthday was 7.0\% (145/2064), and that on other days was 5.6\% (54824/978 812). After adjusting for patient characteristics, patients who underwent surgery on the operating surgeon's birthday had higher adjusted 30 day mortality compared with patients who underwent surgery on other days $(7.2 \% \vee 5.6 \%$; adjusted difference $1.6 \%$, $95 \%$ confidence interval $0.4 \%$ to $2.8 \%$; $\mathrm{P}=0.01$ ) (table 2 ). These findings remained largely consistent after additional adjustment for hospital fixed effects (model 2) or surgeon fixed effects (model 3). For example, after adjustment for both patient characteristics and surgeon fixed effects, 30 day mortality was higher on surgeons' birthdays compared with other days $(6.9 \%$ $v$ 5.6\%; adjusted difference $1.3 \%, 0.1 \%$ to $2.5 \%$; $\mathrm{P}=0.03)$. In an event study analysis, 30 day mortality was higher for surgeries that were performed on a surgeon's birthday compared with other days (fig 1 and supplementary eTable 4).

\section{Secondary analyses}

Findings were qualitatively unaffected by: using in-hospital mortality instead of 30 day mortality; 


\begin{tabular}{|c|c|c|c|}
\hline Characteristics & Surgeon's birthdays & Other days & $P$ value \\
\hline Mean (SD) age (years) & $78.6(8.4)$ & $78.6(8.4)$ & 0.95 \\
\hline Women & $1273(61.7)$ & $607829(62.1)$ & 0.69 \\
\hline \multicolumn{4}{|l|}{ Race or ethnicity: } \\
\hline Black & $115(5.6)$ & $53066(5.4)$ & \multirow{3}{*}{0.90} \\
\hline Hispanic & $88(4.3)$ & $44843(4.6)$ & \\
\hline Others & $61(3.0)$ & $28296(2.9)$ & \\
\hline Mean (SD) of median household income (\$) & $60665(24495)$ & $61072(25028)$ & 0.46 \\
\hline Medicaid status & $334(16.2)$ & $165548(16.9)$ & 0.38 \\
\hline Renal failure & $315(15.3)$ & $154544(15.8)$ & 0.51 \\
\hline Neurological disorders & $274(13.3)$ & $122787(12.5)$ & 0.32 \\
\hline Mental illness & $288(14.0)$ & $138170(14.1)$ & 0.83 \\
\hline Mean (SD) predicted mortality rate* (\%) & $5.5(6.6)$ & $5.6(6.8)$ & 0.35 \\
\hline
\end{tabular}

additionally adjusting for the timing of the surgery; including both hospital and surgeon fixed effects in the same regression models; excluding potentially outlier surgeons with the highest mortality; using logistic regression models instead of linear probability models: using random effects models instead of fixed effects models; restricting our analysis to surgeons who performed procedures on their birthdays; additionally adjusting for the day of the year; or excluding surgeons who were born on the outlier birthdays (supplementary eTables 5-13). Although the differences were not statistically significant for most procedures owing to small sample sizes, point estimates showed higher patient mortality on the operating surgeon's birthday for all procedures included in the stratified analysis except for two: carotid endarterectomy and cholecystectomy and common duct procedures (supplementary eTable 14).

No evidence was found that patients who received surgery on operating surgeons' half birthdays experienced higher mortality compared with patients who underwent surgery on other days, indicating that the findings could not be explained by chance (supplementary eTable 15). Also, the observed increase in patient mortality on surgeons' birthdays was larger than $99.5 \%$ of simulated coefficients obtained by randomly assigning pseudo-birthdays and fitting similar regression models 1000 times (supplementary
eFigure 5). The study findings were qualitatively unaffected when the analysis was restricted to procedures with the highest average mortality or to patients with the highest severity of illness (supplementary eTables 16 and 17). No evidence was found for patient mortality being higher on surgeons' birthdays for elective surgeries (supplementary eTable 18). Also, no evidence was found for complication rates differing for patients who underwent a surgical procedure on the surgeon's birthday, perhaps related to the narrowness of the Agency for Health Research and Quality's Patient Safety Indicators for surgery (supplementary eTable 19).

Patient mortality was found to be higher when surgeons performed many procedures on their birthday, compared with when surgeons performed a smaller number of procedures on their birthday, although the difference was not statistically significant (supplementary eTable 20). The association between surgeon's birthday and patient outcomes did not differ based on milestone birthdays or when the birthdays were on a Friday (supplementary eTables 21 and 22).

\section{Discussion}

Using a national sample of Medicare beneficiaries who underwent common emergency surgical procedures, we found that postoperative 30 day mortality was higher in patients who underwent a surgical procedure

\begin{tabular}{|c|c|c|c|c|c|c|c|c|c|c|}
\hline \multirow[b]{2}{*}{ Day } & \multirow[b]{2}{*}{$\begin{array}{l}\text { No of } \\
\text { procedures }\end{array}$} & \multicolumn{3}{|c|}{ Model 1: patient characteristics* } & \multicolumn{3}{|c|}{$\begin{array}{l}\text { Model 2: patient } \\
\text { characteristics* }+ \text { hospital fixed effects }\end{array}$} & \multicolumn{3}{|c|}{$\begin{array}{l}\text { Model 3: patient } \\
\text { characteristics* }+ \text { surgeon fixed effects }\end{array}$} \\
\hline & & $\begin{array}{l}\text { Adjusted } \\
\text { mortality rate, } \\
\%(95 \% \mathrm{Cl})\end{array}$ & $\begin{array}{l}\text { Adjusted } \\
\text { difference, } \\
\%(95 \% \mathrm{Cl})\end{array}$ & $P$ value & $\begin{array}{l}\text { Adjusted } \\
\text { mortality rate, } \\
\%(95 \% \mathrm{Cl})\end{array}$ & $\begin{array}{l}\text { Adjusted } \\
\text { difference, } \\
\%(95 \% \mathrm{CI})\end{array}$ & P value & $\begin{array}{l}\text { Adjusted } \\
\text { mortality rate, } \\
\%(95 \% \mathrm{Cl})\end{array}$ & $\begin{array}{l}\text { Adjusted } \\
\text { difference, } \\
\%(95 \% \mathrm{Cl})\end{array}$ & $P$ value \\
\hline $\begin{array}{l}\text { Surgeon's } \\
\text { birthday }\end{array}$ & 2064 & $7.2(6.0$ to 8.4$)$ & 1.6 (0.4 to 2.8$)$ & 0.01 & $7.2(6.0$ to 8.4$)$ & 1.6 (0.4 to 2.8$)$ & 0.01 & 6.9 (5.7 to 8.1) & $1.3(0.1$ to 2.5$)$ & 0.03 \\
\hline Other days & 978812 & 5.6 (5.5 to 5.7$)$ & Reference & & $5.6(5.6$ to 5.7$)$ & Reference & & $5.6(5.6$ to 5.6$)$ & Reference & \\
\hline
\end{tabular}




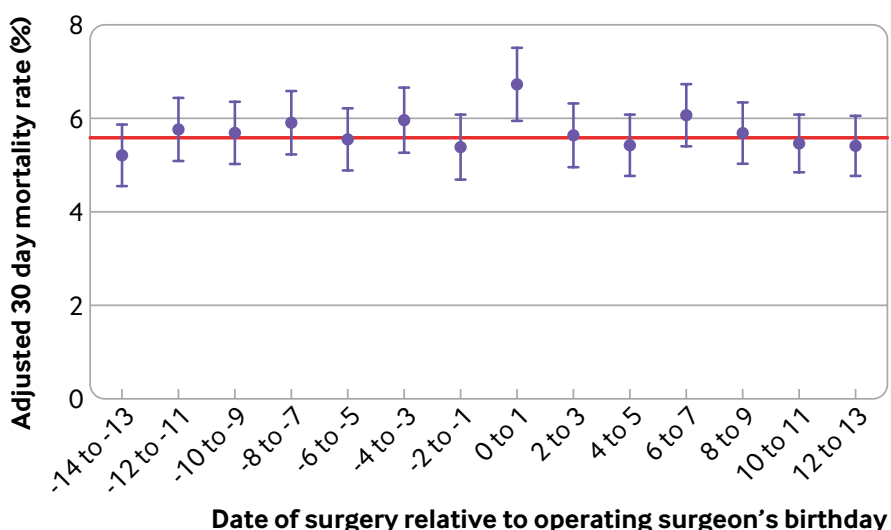

Fig 1 | Adjusted 30 day patient mortality rates from an event study (adjusting for patient characteristics and surgeon fixed effects). Red horizontal line represents adjusted mortality rate for surgical procedures performed on days other than within two weeks of operating surgeon's birthday. Days were grouped into categories of two days to avoid unstable estimates. Error bars show $95 \%$ confidence intervals

on an operating surgeon's birthday compared with patients who received a procedure on other days of the year. This finding persisted in a within surgeon analysis that compared outcomes of patients who underwent surgery on a given surgeon's birthday compared with patients who underwent surgery by that same surgeon on other days of the year. No difference was found in a broad range of patient characteristics, including predicted mortality rates, between patients who underwent surgery on a surgeon's birthday versus other days of the year, indicating that these findings were unlikely to be explained by differences in patient factors. Taken together, these findings suggest that a surgeon's performance might be affected by life events that are not directly related to work, a hypothesis that while intuitive has been otherwise difficult to assess owing to lack of detailed information on events that are potentially distracting to an individual surgeon. Although the average number of surgical procedures performed by each surgeon was similar between birthdays and other days, indicating that surgeons who work on their birthdays do not reduce their operative volume on that day, we found that some surgeons did not work on their birthdays (1805 surgeons performed procedures on their birthday versus 2144 surgeons one day before their birthday and 2027 surgeons one day after their birthday). This does not affect the results of analyses using surgeon fixed effects, as patient outcomes were compared between birthday and nonbirthday surgeries within the same surgeon; however, this does suggest that birthdays are an important enough factor for some surgeons to choose not to operate on that day, which supports the credibility of our assumption that a birthday could be a distracting factor for those surgeons who choose to operate on that day.

The effect size of surgeons' birthday observed in our analysis (1.3 percentage point increase or a $23 \%$ increase in mortality), though substantial, is comparable to the impact of other events, including holidays (eg, Christmas and New Year) and weekends, which have been argued to affect the quality of patient care. ${ }^{50-52}$ For example, patients who were emergently admitted to hospitals on public holidays in Scotland showed a $27 \%$ increase in 30 day mortality compared with patients admitted on other days. ${ }^{50}$ Our use of surgeon birthdays as a "natural experiment" is arguably better than using other distracting events used in previous studies, because those events not only affect physicians' performance but also influence patients' decision to seek care (ie, patients seeking care on these special days might be sicker than those seeking care on other days), as well as hospital staffing. In contrast, patient case mix (it is unlikely that patients know their surgeons' birthday) and hospital staffing are similar on surgeons' birthdays. The estimated effect was also measured with uncertainty, and relationships of a smaller, but non-zero, magnitude cannot be ruled out.

Several potential mechanisms might explain why patient mortality was higher on surgeons' birthdays. First, surgeons could be under relatively higher time pressure-feeling rushed to complete procedures on time-on their birthday compared with other days of the year, because they might have important evening plans to celebrate their birthday. Research suggests that time pressure might impair the ability to avoid errors of intuitive judgment and may cause heuristic decisions during and after operations, which could lead to a higher likelihood of errors and overlooking signals of clinical deterioration in patients. ${ }^{53}$ Time pressure may also increase the risk of confirmation bias ${ }^{55}$-the tendency to gather evidence that confirms pre-existing expectations (or biases) while dismissing or failing to seek contradictory evidence. ${ }^{56}$ In this case, surgeons might, probably unconsciously, gather the information that supports a surgeon's expectation that surgery was performed successfully. Second, conversations related to birthdays with other team members (eg, anesthesiologists, operating room nurses) during surgical procedures could be distracting, leading to medical errors. ${ }^{57}$ Third, surgeons may receive birthday messages on their phones in the operating room (ie, receive a larger total number of messages on birthdays compared with other days), which can be a potential source of distraction, as indicated by previous studies showing that distractions in the operating room are common, including noise (eg, calls from the ward, beeper pages) and conversations not pertinent to the surgical procedure. ${ }^{21-24}$ Fourth, it is possible that surgeons might allow surgical trainees to do more on the surgeon's birthday in order to get home early for a celebration or other birthday related reasons, leading to poorer outcomes. Fifth, "decision fatigue" due to other competing non-work related decisions that may be made on birthdays could make it harder for surgeons to make appropriate decisions during and after procedures. ${ }^{58}$ Finally, it is also possible that postoperative care decisions could differ on surgeons' birthdays. For example, surgeons may be less likely to return to the hospital to see their patients who show 
signs of deterioration if they are having dinner with family and friends, compared with regular evenings.

The major threat to the internal validity of our findings is that surgeons may selectively operate on sicker and more complex patients on their birthday, perhaps because those patients cannot have their procedures delayed. However, this is unlikely to explain our findings because we found that patients who underwent surgery on the surgeon's birthday were similar in all observable characteristics to patients who underwent surgery on other days. Furthermore, severity of illness as measured by predicted mortality, and the number of procedures performed per surgeon, also did not differ based on whether a surgery occurred on a surgeon's birthday compared with other days.

We empirically tested whether physicians' practice patterns and outcomes vary due to life events outside of their work environment, whereas other studies not focused on individual life events have nonetheless shown how physician decisions may be affected by other factors that may systematically lead to distraction or rushing. For example, one study found that clinicians are more likely to prescribe antibiotics to patients with upper respiratory tract infections as the workday progresses, probably because the cumulative cognitive demand of clinical decisions progressively impairs clinician's ability to avoid clinically inappropriate decisions. ${ }^{59}$ Comparable findings were observed for the prescription of opioids as well. ${ }^{60}$ Similarly, one study found that clinicians' ordering of cancer screening tests decreased as the workday progressed..$^{61}$ Outside of healthcare, studies of how judges make decisions about parole, sentence lengths, and immigration have found that their decisions are sensitive to extraneous factors, including taking a food break, experiencing unexpected losses of football games, and an increase in outdoor temperature. ${ }^{29-31}$

Our findings have several implications for clinical practice. First, our results indicate that individual surgeons' performance may be meaningfully influenced by life events outside of their work environment. It may be possible that the patterns we observed extend to other distracting life events. Additional support for surgeons who have potentially distracting events may be warranted to make sure that patients receive high quality surgical care regardless of when undergo surgery. Our findings also indicate how large data can be used to monitor the quality of care and to identify unexpected factors that might influence physicians' clinical performance and patient outcomes.

\section{Limitations of this study}

Our study has limitations. First, although we adjusted for a broad set of patient level confounders and hospital or surgeon fixed effects, we could not eliminate the possibility of unmeasured confounding, as is the case with any observational study. In particular, it is possible that despite showing comparability of patients on the basis of a range of patient characteristics, surgeons might postpone less severe cases and operate on only the most severe cases on their birthdays. Second, as a result of the lack of detailed clinical information in the claims data, we were not able to identify the mechanisms (eg, reductions in operation times or earlier than typical completion of the day's final surgery) through which patients experienced higher mortality when they underwent surgery on surgeons' birthdays. Third, we were not able to analyze the cause of death owing to the lack of information in our data. Finally, we focused on 17 most common procedures received by Medicare patients aged 65-99 years, and therefore the findings might not be generalizable to other patient populations or to other surgical procedures.

\section{Conclusions}

Using national data on Medicare beneficiaries undergoing emergency surgical procedures, we found a higher risk of 30 day mortality after surgery when the operation was performed on a surgeon's birthday. These findings illustrate how large data might be used to assess whether the performance of a surgeon is influenced by life events outside of his or her work environment.

\section{AUTHOR AFFILIATIONS}

${ }^{1}$ Division of General Internal Medicine and Health Services Research, David Geffen School of Medicine at UCLA, 1100 Glendon Avenue Suite 850, Los Angeles, CA, 90024, USA

${ }^{2}$ Graduate School of Business Administration, Keio University, Yokohama, Japan

${ }^{3}$ Department of Health Care Policy, Harvard Medical School, Boston, MA, USA

${ }^{4}$ Department of Medicine, Massachusetts General Hospital, Boston, MA, USA

${ }^{5}$ USC Schaeffer Center for Health Policy \& Economics, Los Angeles, CA, USA

${ }^{6}$ National Bureau of Economic Research, Cambridge, MA, USA ${ }^{7}$ Department of Health Policy and Management, UCLA Fielding School of Public Health, Los Angeles, CA, USA

We thank Ashish K Jha for administrative support and Thomas Tsai, Charles Liu, and Rivfka Shenoy for feedback on our manuscript.

Contributors: All authors conceived and designed the study, analyzed and interpreted the data, and critically revised the manuscript for important intellectual content. HK and YT conducted the statistical analysis. HK and YT are the guarantors. The corresponding author attests that all listed authors meet authorship criteria and that no others meeting the criteria have been omitted.

Funding: This study was supported by the Office of the Director, National Institutes of Health (1DP50D017897, ABJ) and the Japan Society for the Promotion of Science (Grants-in-Aid for Scientific Research, grant No 18J00782, HK). ABJ reports receiving consulting fees unrelated to this work from Pfizer, Hill Rom Services, Bristol Myers Squibb, Novartis, Amgen, Eli Lilly, Vertex Pharmaceuticals, AstraZeneca, Celgene, Tesaro, Sanofi Aventis, Biogen, Precision Health Economics, and Analysis Group. The funding sources had no role in the design and conduct of the study; collection, management, analysis, and interpretation of the data; and preparation, review, or approval of the manuscript.

Competing interests: All authors have completed the ICMJE uniform disclosure form at www.icmje.org/coi_disclosure.pdf and declare: $A B$ J reports receiving consulting fees unrelated to this work from Pfizer, Hill Rom Services, Bristol Myers Squibb, Novartis, Amgen, Eli Lilly, Vertex Pharmaceuticals, AstraZeneca, Celgene, Tesaro, Sanofi Aventis, Biogen, Precision Health Economics, and Analysis Group.

Ethical approval: This study was approved by the University of California, Los Angeles institutional review board (No 19-000954).

Data sharing: No additional data available.

The manuscript's guarantors (HK and YT) affirm that the manuscript is an honest, accurate, and transparent account of the study being reported; that no important aspects of the study have been omitted; 
and that any discrepancies from the study as planned (and, if relevant, registered) have been explained.

Dissemination to participants and related patient and public communities: This study was a retrospective observational study. No patients were involved in setting the research question or the outcome measures, nor were they involved in developing plans for the design or implementation of the study. No patients were asked to advise on interpretation or writing up of results. There are no plans to disseminate the results of the research to study participants or the relevant patient community. The results of this work will be disseminated to the public through institutional press release, ensuing news articles, and an opinion piece written by the study's authors that describe the study's findings for the public.

Provenance and peer review: Not commissioned; externally peer reviewed.

This is an Open Access article distributed in accordance with the Creative Commons Attribution Non Commercial (CC BY-NC 4.0) license, which permits others to distribute, remix, adapt, build upon this work non-commercially, and license their derivative works on different terms, provided the original work is properly cited and the use is non-commercial. See: http://creativecommons.org/licenses/ by-nc/4.0/

1 Shrime MG, Sleemi A, Ravilla TD. Charitable platforms in global surgery: a systematic review of their effectiveness, cost-effectiveness, sustainability, and role training. World J Surg 2015;39:10-20. doi:10.1007/s00268-014-2516-0

2 Shrime MG, Bickler SW, Alkire BC, Mock C. Global burden of surgical disease: an estimation from the provider perspective. Lancet Glob Health 2015:3(Suppl 2):S8-9. doi:10.1016/S2214109X(14)70384-5

3 Jamison DT, Breman JG, Measham AR, et al. Disease control priorities in developing countries. World Bank Publications, 2006.

4 Ghaferi AA, Birkmeyer JD, Dimick JB. Variation in hospital mortality associated with inpatient surgery. N Engl / Med 2009;361:1368-75 doi:10.1056/NEIMsa0903048

5 Nicholas LH, Osborne NH, Birkmeyer JD, Dimick JB. Hospital process compliance and surgical outcomes in medicare beneficiaries. Arch Surg 2010;145:999-1004. doi:10.1001/archsurg.2010.191

6 Reames BN, Birkmeyer NI, Dimick IB, Ghaferi AA. Socioeconomic disparities in mortality after cancer surgery: failure to rescue. JAMA Surg 2014;149:475-81. doi:10.1001/jamasurg.2013.5076

7 Gonzalez AA, Dimick JB, Birkmeyer ID, Ghaferi AA. Understanding the volume-outcome effect in cardiovascular surgery: the role of failure to rescue. JAMA Surg 2014;149:119-23. doi:10.1001/ jamasurg.2013.3649

8 Ghaferi AA, Birkmeyer JD, Dimick JB. Complications, failure to rescue, and mortality with major inpatient surgery in medicare patients. Ann Surg 2009;250:1029-34. doi:10.1097/SLA.0b013e3181bef697

9 Pearse RM, Moreno RP, Bauer P, et al, European Surgical Outcomes Study (EuSOS) group for the Trials groups of the European Society of Intensive Care Medicine and the European Society of Anaesthesiology. Mortality after surgery in Europe: a 7 day cohort study. Lancet 2012;380:1059-65. doi:10.1016/S01406736(12)61148-9

10 Healey MA, Shackford SR, Osler TM, Rogers FB, Burns E. Complications in surgical patients. Arch Surg 2002;137:611-7. discussion 617-8. doi:10.1001/archsurg.137.5.611

11 Schilling PL, Dimick JB, Birkmeyer JD. Prioritizing quality improvement in general surgery. J Am Coll Surg 2008:207:698-704. doi:10.1016/j.jamcollsurg.2008.06.138

12 Birkmeyer JD, Gust C, Dimick JB, Birkmeyer NJ, Skinner JS. Hospital quality and the cost of inpatient surgery in the United States. Ann Surg 2012;255:1-5. doi:10.1097/SLA.0b013e3182402c17

13 Wong SL, Revels SL, Yin H, et al. Variation in hospital mortality rates with inpatient cancer surgery. Ann Surg 2015;261:632-6. doi:10.1097/SLA.0000000000000690

14 Scally CP, Thumma JR, Birkmeyer JD, Dimick JB. Impact of Surgical Quality Improvement on Payments in Medicare Patients. Ann Surg 2015;262:249-52 doi:10.1097/SLA.0000000000001069

15 International Surgical Outcomes Study group. Global patient outcomes after elective surgery: prospective cohort study in 27 lowmiddle- and high-income countries. Br J Anaesth 2016;117:601-9. doi:10.1093/bja/aew316

16 Gawande AA, Thomas E), Zinner MJ, Brennan TA. The incidence and nature of surgical adverse events in Colorado and Utah in 1992 Surgery 1999:126:66-75. doi:10.1067/msy.1999.98664

17 Kable AK, Gibberd RW, Spigelman AD. Adverse events in surgical patients in Australia. Int J Qual Health Care 2002;14:269-76. doi:10.1093/intahc/14.4.269

18 Birkmeyer JD, Stukel TA, Siewers AE, Goodney PP, Wennberg DE, Lucas FL. Surgeon volume and operative mortality in the United States. N Engl J Med 2003;349:2117-27. doi:10.1056/NEJMsa035205
19 Birkmeyer JD, Siewers AE, Finlayson EVA, et al. Hospital volume and surgical mortality in the United States. N Engl J Med 2002;346:112837. doi:10.1056/NEIMsa012337

20 Gruen RL, Pitt V, Green S, Parkhill A, Campbell D, Jolley D. The effect of provider case volume on cancer mortality: systematic review and meta-analysis. CA Cancer J Clin 2009;59:192-211. doi:10.3322/ caac. 20018

21 Shapiro RA, Berland T. Noise in the operating room. N EnglJ Med 1972;287:1236-8. doi:10.1056/NEJM197212142872407

22 Hodge B, Thompson JF. Noise pollution in the operating theatre. Lancet 1990;335:891-4. doi:10.1016/0140-6736(90)90486-0

23 Healey AN, Sevdalis N, Vincent CA. Measuring intra-operative interference from distraction and interruption observed in the operating theatre. Ergonomics 2006;49:589-604 doi:10.1080/00140130600568899

24 Persoon MC, Broos HJ, Witjes JA, Hendrikx AJ, Scherpbier AJ. The effect of distractions in the operating room during endourological procedures. Surg Endosc 2011;25:437-43. doi:10.1007/s00464010-1186-8

25 Feuerbacher RL, Funk KH, Spight DH, Diggs BS, Hunter JG. Realistic distractions and interruptions that impair simulated surgical performance by novice surgeons. Arch Surg 2012;147:1026-30. doi:10.1001/archsurg.2012.1480

26 Conrad C, Konuk Y, Werner PD, et al. A quality improvement study on avoidable stressors and countermeasures affecting surgical motor performance and learning. Ann Surg 2012;255:1190-4. doi:10.1097/SLA.0b013e318250b332

27 Siu K-C, Suh IH, Mukherjee M, Oleynikov D, Stergiou N. The impact of environmental noise on robot-assisted laparoscopic surgical performance. Surgery 2010;147:107-13. doi:10.1016/j. surg.2009.08.010

28 Goodell KH, Cao CG, Schwaitzberg SD. Effects of cognitive distraction on performance of laparoscopic surgical tasks. / Laparoendosc Adv Surg Tech A 2006;16:94-8. doi:10.1089/lap.2006.16.94

29 Danziger S, Levav J, Avnaim-Pesso L. Extraneous factors in judicial decisions. Proc Natl Acad Sci U S A 2011;108:6889-92. doi:10.1073/pnas.1018033108

30 Eren O, Mocan N. Emotional Judges and Unlucky Juveniles. Am Econ J Appl Econ 2018;10:171-205. doi:10.1257/app.20160390

31 Heyes A, Saberian S. Temperature and Decisions: Evidence from 207000 Court Cases. Am Econ J Appl Econ 2019;11:238-65. doi:10.1257/app.20170223

32 Tsugawa Y, Jena AB, Orav EJ, et al. Age and sex of surgeons and mortality of older surgical patients: observational study. BMJ 2018;361:k1343. doi:10.1136/bmj.k1343

33 Tsugawa Y, Dimick JB, Jena AB, et al. Comparison of Patient Outcomes of Surgeons Who Are US Versus International Medical Graduates. Ann Surg 2019; published online 10 Dec. doi:10.1097/ SLA.0000000000003736

34 Moja L, Piatti A, Pecoraro V, et al. Timing matters in hip fracture surgery: patients operated within 48 hours have better outcomes. A meta-analysis and meta-regression of over 190,000 patients. PLoS One 2012;7:e46175. doi:10.1371/journal.pone.0046175

35 Sahni NR, Dalton M, Cutler DM, Birkmeyer JD, Chandra A. Surgeon specialization and operative mortality in United States: retrospective analysis. BM/ 2016;354:i3571. doi:10.1136/bmj.i3571

36 Shoda N, Yasunaga H, Horiguchi H, et al. Risk factors affecting inhospital mortality after hip fracture: retrospective analysis using the Japanese Diagnosis Procedure Combination Database. BMJ Open 2012:2:e000416 doi:10.1136/bmiopen-2011-000416

37 Waljee JF, Greenfield LJ, Dimick JB, Birkmeyer JD. Surgeon age and operative mortality in the United States. Ann Surg 2006;244:35362. doi:10.1097/01.sla.0000234803.11991.6d

38 Finks JF, Osborne NH, Birkmeyer JD. Trends in hospital volume and operative mortality for high-risk surgery. N Engl J Med 2011:364:2128-37. doi:10.1056/NEIMsa1010705

39 Miller ME, Welch WP, Welch HG. The impact of practicing in multiple hospitals on physician profiles. Med Care 1996;34:455-62 doi:10.1097/00005650-199605000-00007

40 Centers for Medicare \& Medicaid Services. Medicare Data on Provide Practice and Specialty (MD-PPAS) https://www.resdac.org/cms-data/ files/md-ppas/data-documentation (accessed 3 November 2020).

41 Research Data Assistance Center. Death Information in the Research Identifiable Medicare Data 2016 https://www.resdac.org/ resconnect/articles/117 (accessed 2 November 2017)

42 Elixhauser A, Steiner C, Harris DR, Coffey RM. Comorbidity measures for use with administrative data. Med Care 1998;36:8-27. doi:10.1097/00005650-199801000-00004

43 Aylin P, Alexandrescu R, Jen MH, Mayer EK, Bottle A. Day of week of procedure and 30 day mortality for elective surgery: retrospective analysis of hospital episode statistics. BMJ 2013;346:f2424. doi:10.1136/bmj.f2424

44 Gillies MA, Lone NI, Pearse RM, et al. Effect of day of the week on short- and long-term mortality after emergency general surgery. $\mathrm{Br}$ J Surg 2017;104:936-45. doi:10.1002/bjs.10507 
45 Gardiner JC, Luo Z, Roman LA. Fixed effects, random effects and GEE: what are the differences?Stat Med 2009;28:221-39. doi:10.1002/ sim. 3478

46 Gunasekara FI, Richardson K, Carter K, Blakely T. Fixed effects analysis of repeated measures data. Int J Epidemiol 2014;43:264-9. doi:10.1093/ije/dyt221

47 Hellevik O. Linear versus logistic regression when the dependent variable is a dichotomy. Qual Quant 2009;43:59-74. doi:10.1007/ s11135-007-9077-3

48 Wooldridge JM. Econometric Analysis of Cross Section and Panel Data. The MIT Press, 2010.

49 Williams R. Using the margins command to estimate and interpret adjusted predictions and marginal effects. Stata / 2012;12:308-31. doi:10.1177/1536867X1201200209

50 Smith S, Allan A, Greenlaw N, Finlay S, Isles C. Emergency medical admissions, deaths at weekends and the public holiday effect. Cohort study. Emerg Med / 2014;31:30-4. doi:10.1136/ emermed-2012-201881

51 Bell CM, Redelmeier DA. Mortality among patients admitted to hospitals on weekends as compared with weekdays. N Engl J Med 2001;345:663-8. doi:10.1056/NEJMsa003376

52 Phillips DP, Jarvinen JR, Abramson IS, Phillips RR. Cardiac mortality is higher around Christmas and New Year's than at any other time: the holidays as a risk factor for death. Circulation 2004;110:3781-8. doi:10.1161/01.CIR.0000151424.02045.F7

53 Kahneman D. Maps of Bounded Rationality: Psychology for Behavioral Economics. Am Econ Rev 2003;93:1449-75. doi:10.1257/000282803322655392

54 Finucane ML, Alhakami A, Slovic P, et al. The affect heuristic in judgments of risks and benefits. J Behav Decis Making 2000;13:1 17. doi:10.1002/(SICI)1099-0771(200001/03)13:1<1::AIDBDM333>3.0.CO;2-S
55 Ask K, Granhag PA. Motivational Bias in Criminal Investigators Judgments of Witness Reliability1. J Appl Soc Psychol 2007;37:56191. doi:10.1111/j.1559-1816.2007.00175.x

56 American Psychological Association. APA Dictionary of Psychology https://dictionary.apa.org/confirmation-bias (accessed 27 March 2020).

57 Caird JK, Simmons SM, Wiley K, Johnston KA, Horrey WJ. Does Talking on a Cell Phone, With a Passenger, or Dialing Affect Driving Performance? An Updated Systematic Review and MetaAnalysis of Experimental Studies. Hum Factors 2018;60:101-33. doi:10.1177/0018720817748145

58 Vohs KD, Baumeister RF, Schmeichel BJ, Twenge JM, Nelson NM, Tice DM. Making choices impairs subsequent self-control: a limitedresource account of decision making, self-regulation, and active initiative. J Pers Soc Psychol 2008;94:883-98. doi:10.1037/00223514.94.5.883

59 Linder JA, Doctor JN, Friedberg MW, et al. Time of day and the decision to prescribe antibiotics. JAMA Intern Med 2014;174:202931. doi:10.1001/jamainternmed.2014.5225

60 Neprash HT, Barnett ML. Association of Primary Care Clinic Appointment Time With Opioid Prescribing. JAMA Netw Open 2019;2:e1910373. doi:10.1001/ jamanetworkopen.2019.10373

61 Hsiang EY, Mehta SJ, Small DS, et al. Association of Primary Care Clinic Appointment Time With Clinician Ordering and Patient Completion of Breast and Colorectal Cance Screening. JAMA Netw Open 2019;2:e193403. doi:10.1001/ jamanetworkopen.2019.3403

Supplementary information: additional eTables 1-22 and eFigures 1-5 